\title{
Influência da data de validade nas decisões de compra e consumo de produtos alimentícios
}

Flávio Bressan *

Professor, Centro Paula Souza - CPS, Faculdades de Tecnologia - FATEC, São Paulo, Brasil.

bremat@terra.com.br

Geraldo Luciano Toledo

Full Professor, Faculdade de Economia e Administração - FEA, Universidade de São Paulo, São Paulo, Brasil.

gltoledo@usp.br

\section{Resumo}

0 trabalho investigou a influência da data de validade nas atitudes, decisões de compra, e consumo de alimentos. Realizaram-se 12 entrevistas e um levantamento ( $n=199$ ), cujos dados foram submetidos à análise fatorial, Teste t e análise de variância (ANOVA). Os resultados indicaram relação entre o conhecimento sobre conservação e consumo, validade e consumo de alimentos, mas não sobre o consumo de alimentos vencidos e nem relação entre riscos, compra e consumo destes alimentos vencidos. Indicaram, também, que os entrevistados parecem basear suas decisões mais na aparência do alimento e na experiência pessoal do que nos riscos percebidos sobre validade vencida, o que é um indicativo da necessidade de ações educacionais para torná-la fator de influência nas decisões de compra e consumo de alimentos.

Palavras-chave: data de validade; compra de alimentos; consumo de alimentos; riscos alimentares.

\section{La influencia de la fecha de vencimiento sobre las decisiones de compra y consumo de productos alimentarios}

\section{Resumen}

El trabajo investigó la influencia de la fecha de vencimiento en las actitudes, decisiones de compra y consumo de alimentos. Se realizaron 12 entrevistas y una encuesta ( $\mathrm{n}=199)$, cuyos datos fueron sometidos a análisis factorial, prueba t y análisis de varianza (ANOVA). Los resultados indicaron relaciones entre conocimiento sobre conservación y consumo y sobre la validez y el consumo de alimentos, pero no se encontró relación con el consumo de alimentos caducados ni entre riesgos y compra y consumo de alimentos caducados. Indicaron, además, que los entrevistados parecen basar sus decisiones más en la apariencia del alimento y en la experiencia personal que en los riesgos percibidos de vigencia vencida, lo que indica la necesidad de acciones educativas para convertirla en un factor de influencia en las decisiones de compra y consumo de alimentos.

Palabras clave: fecha de vencimiento; compra de alimentos; consumo de alimentos; riesgos alimentarios

\section{The influence of expiration date on purchase and consumption decisions of food products}

\section{Abstract}

The work investigated the influence of expiration data on attitudes, purchasing decisions, and food consumption. Twelve interviews and one survey ( $n=199$ ), whose data were submitted to a factorial analysis, test $t$, and analysis of variance (ANOVA), were carried out. The results indicated a relationship between the knowledge on conservation and consumption, on validity and consumption of food, but not with the consumption of expired foods, nor the relationship between risks, purchase, and consumption of expired food. They also indicated that the interviewees seem to base their decisions more on the appearance of food and their personal experience than on the perceived risks on expired validity. This indicates the need for educational actions to make the expired validity an issue of influence on purchase decisions and food consumption.

Keywords: expiration date; purchase of food; consumption of food; food risks.

* Autor para dirigir correspondência.

Classificações JEL: M10; M30; M31.

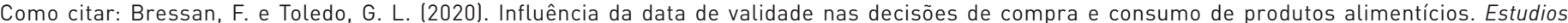
Gerenciales, 36(157), 439-453. https://doi.org/10.18046/j.estger.2020.157.3909

DOI: https://doi.org/10.18046/j.estger.2020.157.3909

Recebido: 20-fev-2020

Aceito: 30 -out-2020

Publicado: 30-dez-2020

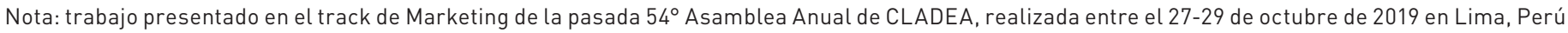




\section{Introdução}

O comportamento de compra e consumo de alimentos, é uma atividade que resulta em prejuízos para os consumidores, caso eles não deem a devida atenção à data de validade: seja na compra, seja no consumo de alimentos. Com relação à decisão de compra de alimentos, a primeira informação visual acessível ao consumidor sobre um alimento é o seu rótulo (Scholes, 2010; Lindemann, Silva, César e Mendoza-Sassi, 2016), que “é toda inscrição, legenda, imagem ou toda matéria descritiva ou gráfica que esteja escrita, impressa, estampada, gravada, gravada em relevo, litografada ou colada sobre a embalagem do alimento" (Agência Nacional de Vigilância Sanitária-ANVISA, 2019). Ele objetiva diferenciar e promover o produto e capturar a atenção dos consumidores; fornece dados sobre a marca, o fabricante, os ingredientes e o valor nutricional, assim como o modo de preparo e o uso apropriado; o lote, a data de fabricação e de validade. Estas informações visam propiciar uma oportunidade para que se conheça a composição do alimento, seus nutrientes e sua energia, além de explicações pertinentes à manutenção da saúde (Ferreira e Lanfer-Marquez, 2007). Elas ajudam os consumidores a conhecer o produto, seus ingredientes, a compará-los com similares, e a verificar a data de validade, cuja finalidade é propiciar informações sobre o frescor e a conservação, proteger os consumidores em suas decisões de compra e consumo, em sua segurança alimentar, e contra os riscos do consumo de alimentos com a validade vencida (Harcar e Karakaya, 2005; Li, Messer e Kaiser, 2020).

Apesar de reconhecerem os riscos e a gravidade do consumo de alimentos vencidos e afirmarem que verificam a data de validade, muitas vezes, os consumidores parecem não dar importância, ou não saber, o significado deste termo (Hall-Phillips e Shah, 2017) e os riscos envolvidos na sua compra e consumo; e nem como proceder em relação a um produto que tenha passado apenas um dia da data do vencimento (Tsiros e Heilman, 2005; Lindemann et al., 2016). Assim, a questão a ser endereçada neste trabalho, pode ser definida como: "Qual a influência da data de validade nas decisões de compra e no consumo de alimentos?"

Para esta finalidade, foi realizado um levantamento junto a uma amostra de fluxo, composta por 199 respondentes, sendo que, deles, 54,3\% eram homens e $45,7 \%$ eram mulheres. Os dados foram submetidos à análise fatorial exploratória (Análise dos Componentes Principais), à análise de confiabilidade (a de Cronbach) e ao teste de igualdade de médias (Teste $t$ e análise de variância - ANOVA).

Sua justificativa está no fato de que investigar e ampliar a compreensão sobre o conhecimento e o comportamento dos consumidores em relação à data de validade, pode propiciar uma base para aprimorar políticas públicas sobre saúde alimentar, e desenvolver programas educacionais que visem informar, esclarecer dúvidas e mudar equívocos; orientar as decisões na compra e no consumo, e auxiliar na redução de problemas de saúde, de sofrimento e de perdas decorrentes do consumo de alimentos com a validade vencida.

Neste contexto, este estudo objetivou examinar o conhecimento dos consumidores sobre a conservação le contaminaçãol de alimentos, sobre a data de validade e sobre os riscos que ela envolve. Objetivou-se examinar, também, a conferência da validade quando da compra e consumo, o consumo de alimentos vencidos, e a relação entre este conhecimento e os comportamentos durante a compra e o consumo de alimentos. Objetivouse, ainda, examinar se as variáveis "gênero", “idade”, "escolaridade" e "renda", constituem filtros adequados para a segmentação dos consumidores.

Para isso, aborda-se o conhecimento sobre a conservação de alimentos, sobre a data de validade e sobre os riscos e perigos associados ao consumo de alimentos com a data de validade vencida, que, de acordo com a Teoria da Ação Racional e da Teoria do Comportamento Planejado (Ajzen e Fishbein, 1977; Ajzen, 2012; Iwaya e Steil, 2019), é uma das variáveis usadas para prever as decisões e comportamentos das pessoas. Em seguida, discute-se a verificação e conferência da validade quando da compra e consumo de alimentos, o consumo de alimentos com a validade vencida, e a opinião dos outros significativos - familiares e amigos em relação à conferência e consumo de alimentos com a validade vencida, uma vez que eles exercem influência nas decisões de compra e consumo de alimentos (Ajzen, 2020).

Desta forma, o que se objetiva é, de um lado, contribuir para ampliar a compreensão do conhecimento e do comportamento do consumidor e, de outro, alertar as empresas para o fato de que, com o aumento do conhecimento e da relevância destas datas, elas devem gerenciar a precisão destas e torná-la mais facilmente visíveis e legíveis, usando-as para a promoção de produtos próximos ao vencimento e possibilitando, assim, o acesso ao consumo por parte de consumidores que, em condições normais de preço de venda, não o teriam.

A venda de produtos vencidos diminuirá a confiança do consumidor em uma marca e no distribuidor que - vende. Muitas empresas passaram a perceber a importância da precisão da data de validade dos produtos e têm tentado tornar estas datas mais visíveis e legíveis. Ademais, nestes tempos de mudança de comportamento do consumidor e de pandemia (Sheth, 2020), a data de validade, fator de confiabilidade da marca e do distribuidor, pode se tornar um fator decisivo nas decisões de compra de alimentos (Kim e Eun Huh, 2019).

Este artigo está estruturado em cinco seções, além da introdução. A próxima seção apresenta uma revisão da literatura sobre o conhecimento do consumidor - conservação de alimentos, data de validade e riscos; sobre o processo de decisão de compra de alimentos, sobre a verificação e conferência da data de validade e consumo de produtos com data de validade vencida. Nas seções seguintes, são apresentados os procedimentos metodológicos. Os dados são analisados e as considerações finais são feitas. Na última seção, são discutidas as implicações teóricas e práticas e são sugeridos mais estudos. 


\section{Fundamentação teórica}

Esta seção apresenta a base conceitual usada para apoiar e orientar o desenvolvimento do trabalho. Aqui são abordados estudos relacionados com a data de validade dos alimentos, abordando o conhecimento envolvido na compra e consumo de alimentos no que se refere à conservação, data de validade e riscos à saúde. Seu objetivo é o estabelecimento de referências para a elaboração e análise das proposições que serão apresentadas nos tópicos seguintes.

\subsection{O Conhecimento do consumidor: conservação, data de validade e riscos}

\subsubsection{Conhecimento sobre a conservação (e contaminação) de alimentos}

Este conhecimento está relacionado com a prevenção de doenças alimentares (Vasconcelos e Melo, 2016). Doença alimentar é toda doença causada ou transmitida pela ingestão de alimento ou água, seja ela de natureza tóxica ou infecciosa, incluindo aquelas causadas por agentes químicos, físicos e microbiológicos presentes nos alimentos e/ou na água. (Griffith, 2006; World Health Organization - WHO, 2017). Mesmo com exame cuidadoso, o consumo de alimentos pode ser fonte de doenças, pois a contaminação e a proliferação de patógenos, produtores de infecções ou de toxinas, podem causar problemas de saúde por intoxicação alimentar que podem levar a óbito (Grunert, 2005; Griffith, 2006; Bernardes, Souza Facioli, Ferreira, Costa e de Sá, 2018). Sob a ótica da segurança alimentar (Marins, Tancredi e Gemal, 2014), estes cuidados com a conservação objetivam prevenir a contaminação, a qual pode ocorrer ao longo da cadeia de produção, processamento, armazenagem, exposição e distribuição, cada vez mais internacionais, cuja consequência é a exposição das pessoas a riscos de doenças (Tsiros e Heilman, 2005; Konuk, 2015); por outro lado, pode reduzir a sua confiança e comprometer, de forma irremediável, produtos, marcas e distribuidores (Grunert, 2005; Griffith, 2006; Johnson, 2009; Samotyja, 2015).

De acordo com o U.S. Center for Disease Control and Prevention (CDCP, 2010), cerca de 30\% da população dos países industrializados sofrem algum tipo de contaminação e, no mundo, estima-se que 600 milhões - quase $1 \mathrm{em}$ cada 10 pessoas no mundo adoecem depois de ingerir alimentos contaminados. 420 mil morrem a cada ano, resultando na perda de 33 milhões de anos de vida saudável (WHO, 2017).

Por causa disto, a legislação, as autoridades sanitárias e as empresas, têm desenvolvido esforços no estabelecimento e manutenção de um sistema de controle e vigilância no processo, na fabricação, e na comercialização de produtos alimentícios (Figueiredo e Csillag, 2010). As possibilidades de contaminação podem ocorrer antes da compra - responsabilidade dos produtores e distribuidores - e depois da compra responsabilidade dos consumidores (Tabela 1).
Tabela 1. Possibilidades de contaminação dos alimentos

\begin{tabular}{ll}
\hline Antes da compra & Após a compra \\
\hline Produção e processamento & Transporte \\
- Agrícola & - Do ponto de venda para a residência \\
- Industrialização & - Embalagem \\
- Embalagem & - Tempo e temperatura \\
Distribuição & Armazenagem: \\
Transporte & - Dispensa \\
- Da produção para o centro de & - Geladeira \\
distribuição & - Congelador \\
- Do centro de distribuição para & - Freezer \\
o varejo & Preparação \\
- Do freezer para a exposição (e & - Manipulação / lavagem \\
vice versa) & - Cocção \\
Armazenagem & - Uso de utensílios \\
- Produtor & - Data de validade vencida \\
- Distribuidor & Consumo \\
- Varejo & - Data de validade vencida \\
Decisão de compra & - Utensílios \\
- Qualidade (deteriorado) & - Louças \\
- Frescor (freshness) & - Descarte \\
- Aparência & \\
- Data de validade vencida & \\
\hline
\end{tabular}

Fonte: adaptado de Grunert (2005).

Mas, estes esforços podem ser inócuos se os consumidores não fizerem a sua parte evitando riscos e comprando produtos seguros, armazenando-os, preparando-os, manipulando-os e cosendo-os de forma correta em suas residências (Kennedy, Jackson, Cowan, Blair, McDowekk e Bolton, 2005; Zandonadi, Botelho, Sávio, Akutsu e Araújo, 2007). É o caso da compra de um pacote de carne moída in natura, dentro da validade, que permanece dentro do carro por um tempo relativamente longo em um dia de elevada temperatura e que, nestas condições, apesar de estar dentro da validade, provavelmente não apresentará características seguras para ser ingerido (Gish, 2009).

Ajuda também a compreender a diferença entre conservar os alimentos na geladeira e no freezer, pois, o efeito do congelamento no freezer, a uma temperatura ao redor de $-18 \mathrm{C}^{\circ}$, é a ideal para a redução ou a inativação dos microrganismos (Damen e Steenbekkers, 2007). Desta forma, o conhecimento sobre a conservação de alimentos pode levar a um consumo mais cuidadoso, reduzindo os riscos de contaminação após a compra: seja no transporte, armazenagem, preparação ou consumo dentro das residências (Cunha, Pinto de Moura, Lopes, do Céu Santos e Silva, 2010). Em relação à data de validade, é de se esperar que este conhecimento tenha influência sobre a sua conferência quando da compra e sobre consumo de alimentos. Isto conduz às seguintes proposições:

- P1: o conhecimento sobre a conservação de alimentos influencia a conferência da data de validade.

- P2: o conhecimento sobre a conservação de alimentos influencia o comportamento de consumo de alimentos com data de validade vencida. 


\subsubsection{Conhecimento sobre a data de validade}

A validade de um alimento se refere à garantia de estabilidade de seus ingredientes e nutrientes, além das condições desejáveis em relação a seus aspectos físico-químicos, expressos, de acordo com a legislação, pela data de validade. Os cálculos, procedimentos, testes e análises para sua determinação, são feitos em laboratórios, por meio de testes práticos, com base no período de tempo após o qual ocorre a degradação de alguns de seus componentes, tais como açúcares, proteínas e carboidratos (Andrade, 2006). Seu objetivo é assegurar que os alimentos, estando dentro da validade e conservados adequadamente, conservem as suas qualidades nutricionais e sanitárias (Gish, 2009). Indicadas pelas expressões "consumir antes de...", "válido até...", "validade...", "Vence (em)...", "vencimento...", "venc...", "consumir preferencialmente antes de...", "val..." (Diário Oficial da União, 1998), a validade indica o fim da garantia de que o alimento não tenha sofrido alterações que deteriorem suas características nutricionais e sua qualidade, e que possam causar problemas de saúde.

0 uso deste conhecimento nas decisões de compra e consumo, pode ajudar na segurança alimentar e proporcionar, até certo ponto, proteção contra os riscos de saúde a decorrentes do consumo de alimentos com validade vencida (Harcar e Karakaya, 2005). Como o conhecimento sobre contaminação é um dos fatores que predispõem a realização da conferência da data de validade, seja na compra ou no consumo, e, como o conhecimento (Ajzen, 2020; Ajzen, 2012) é uma das variáveis usadas para prever as decisões e comportamentos das pessoas, torna possível estabelecer as seguintes proposições:

- P3: o conhecimento sobre a data de validade dos alimentos influencia a frequência de conferência da data de validade.

- P4: o conhecimento sobre a data de validade dos alimentos influencia o comportamento de consumo de alimentos com data de validade vencida.

\subsubsection{Conhecimentos sobre os riscos e perigos associados} ao consumo de alimentos com a data de validade vencida

Os processos de escolha, de compra, de processamento e de consumo de alimentos, parecem sofrer maior influência do conhecimento e da interpretação das características e das condições dos alimentos, mais do que as suas propriedades físicas e alimentares. Estes processos sempre envolvem riscos, entendidos como efeitos negativos não-previstos, associados a um determinado produto ou marca (Tsiros e Heilman, 2005). Alguns destes riscos (Tabela 1), podem ser apenas desagradáveis ou embaraçosos - como os riscos sociais - enquanto outros, podem ser prejudiciais - como os de intoxicação alimentar -, cujos sintomas podem ser um mal-estar, dor abdominal, diarreia e vômito, podendo, em casos agudos, chegar a óbito (Johnson, 2009).

0 conhecimento dos riscos e sua percepção, tanto na compra como no consumo, advém da interpretação psicológica a qual irá influenciar nas atitudes e comportamentos dos consumidores e tem consequências tanto para o seu bem-estar, como para a eficiência e eficácia da cadeia de suprimento e consumo dos alimentos (Yeung e Morris, 2001; Espejel, Fandos e Flavián, 2009). Conhecer os riscos e perigos pode propiciar o desenvolvimento de crenças sobre as consequências do consumo desses alimentos que iriam fortalecer a intenção e motivação para um comportamento adequado tanto na compra, como no consumo de alimentos. Estudos sugerem que a percepção de risco é uma variável poderosa para explicar o comportamento dos consumidores, uma vez que eles estão frequentemente mais motivados a evitar erros do que a maximizar os benefícios da compra (Mitchell, 1999). Como afirma Ajzen (2012), quanto mais fortemente uma pessoa acreditar que certo comportamento irá conduzir a determinado resultado, e quanto mais este resultado for significativo para ela, mais forte será a intenção em apresentar o comportamento em questão. Dispor de conhecimento adequado sobre os riscos relativos à data de validade pode ser de valia para gerar crenças que darão suporte a um comportamento adequado tanto na compra, quanto no consumo desses alimentos.

A percepção de riscos leva os consumidores a buscarem informações antes de comprar alimentos (Blackwell, Minard e Engel, 2005) e a pesquisarem seus atributos antes da compra (Espejel et al., 2009). Esta pesquisa pode ser restrita à verificação da data de validade que, por estar relacionada com a percepção de qualidade, pode ser, até certo ponto, uma indicação do risco à saúde associado à qualidade dos produtos, na medida em que se aproximam do vencimento (Tsiros e Heilman, 2005). Isto pode ser um indicador de que quanto maior for o conhecimento e a percepção de risco de contaminação, maior será a frequência com que se verificará a data de validada antes da compra e do consumo (Beneke, Greene, Lok e Mallet, 2012). Disto podese propor que exista uma relação entre o conhecimento sobre os riscos associados aos alimentos e a conferência e consumo de alimentos com a data de validade vencida:

- P5: o conhecimento sobre os riscos associados à data de validade dos alimentos influencia a frequência de conferência da data de validade.

- P6: o conhecimento sobre os riscos associados à data de validade dos alimentos influencia o comportamento de consumo de alimentos com data de validade vencida.

\subsection{O comportamento de compra e consumo de alimentos}

O Modelo de Blackwell, Minard e Engel (2005) descreve o processo de decisão de compra e consumo, desde a percepção da necessidade até a avaliação pósconsumo. Ressalta a avaliação das opções por meio da 
comparação dos atributos, com seus conhecimentos, padrões e especificações, e experiência, sob a influência das diferenças individuais, de fatores do meio ambiente e da situação, resultando na definição de um produto específico que se adequa às necessidades, valores e estilo de vida. 0 processo de decisão, em algumas vezes, pode ser complexo, mais lento e demorado Processo Decisório Extensivo; em outras, pode ser mais simples, requerendo pouco tempo e esforço do consumidor - Processo Decisório Limitado; pode ser, também, uma compra rotineira, feita quase que "de maneira automática”. A extensão do processo decisório está relacionada ao grau de envolvimento, resultante do nível de importância percebida ou do interesse envolvido na compra ou consumo.

Fator chave no comportamento do consumidor, o grau de envolvimento, muitas vezes, resulta de uma combinação de conhecimento, necessidades, valores e interesses que, correlacionada com variáveis situacionais (Guthrie e Kim, 2009), influencia as atitudes e comportamentos dos consumidores (Espejel et al., 2009). Ele é eliciado por estímulos que auxiliam o consumidor a tomar decisões, possibilitando classificar essas decisões em duas categorias: alto e baixo grau de envolvimento (Kotler e Armstrong, 2010; Guthrie e Kim, 2009; Espejel et al., 2009; Barcellos, Krystallis, de Melo Saab, Kügler e Grunert, 2011). Assim, compreender o processo de compra e consumo de alimentos requer compreender - grau de envolvimento do consumidor, pois muitos consumidores não estão conscientes ou não aceitam que uma grande parte dos problemas de saúde derivados do consumo de produtos alimentícios é causada por eles mesmos e originada em casa (Beumer e Kusumaningrum, 2003).

\subsubsection{O processo de decisão de compra de alimentos}

De modo geral, a compra de alimentos é considerada um processo de baixo envolvimento e a maior parte dessas decisões é tomada pelo processo decisório simplificado. Em muitas ocasiões, parte-se do reconhecimento da necessidade de compra, limitando a busca de informações às marcas conhecidas e disponíveis ou mesmo aos pontos de venda usuais (Beumer e Kusumaningrum, 2003). A satisfação obtida, pode levar ao uso habitual ou a uma compra por inércia, com uma busca negligente de informação e pouca comparação entre as marcas (Guthrie e Kim, 2009; Espejel et al., 2009). 0 baixo envolvimento, pode resultar do reduzido potencial do alimento em expressar a sua autoimagem, do baixo custo relativo e da baixa pressão social em relação à satisfação com a escolha (Verbeke e Vackier, 2005).

Contudo deve-se ressaltar que, para produtos com imagem desfavorável com risco de perdas e custos elevados, ou produtos e marcas com valor simbólico ou que desempenham papel relevante para a autoimagem, por exemplo, este baixo envolvimento não se sustenta (Espejel et al., 2009). Mudanças como o aumento de renda, a ascensão à classe média, as preocupações com a saúde e a estética corporal, realçaram o conteúdo simbólico da alimentação. A maior disponibilização de alimentos orgânicos (De Moura, Nogueira e Gouvêa, 2012), notícias sobre a incorporação de alimentos transgênicos e a repercussão de crises alimentares lepisódio da "carne fraca"), parecem ter tido, como efeito, a elevação do envolvimento dos consumidores com a qualidade e com a data de validade na compra e consumo de alimentos.

Assim, investigar a influência da data de validade nas decisões de compra e consumo de alimentos, pode revelar a importância a ela atribuída pelos consumidores, oferecer orientações sobre o comportamento deles e seus hábitos de compra de alimentos, e sobre o consumo desses alimentos que, por exemplo, se encontrem dentro de suas geladeiras. Isto é importante também por ser um tema relacionado à saúde pública, às perdas pessoais, sociais e econômicas e às despesas com tratamento de problemas derivados do consumo de alimentos com data de validade vencida.

Todos estes aspectos indicam a oportunidade e a conveniência de se investigar os comportamentos de conferência da data de validade dos alimentos e a percepção ou crença em relação ao consumo de produtos alimentícios com data de validade vencida, por parte de outros significativos, ou seja, familiares e amigos.

\subsubsection{Verificação e conferência da data de validade}

Verificar a validade antes da compra ou consumo de alimentos, ajuda a evitar a ingestão de alimentos com esta data vencida e a prevenir os riscos a ela relacionados, podendo ser um indicador da importância atribuída à compra e consumo de produtos que não os exponham a perigos de contaminação quando consumidos. A não-verificação desta data pode ser um indicador da necessidade de informação e educação sobre o significado e importância desta data em sua segurança alimentar (Knight, 2010). A experiência bem-sucedida com alimentos, cria familiaridade com marcas e produtos costumeiros. Esta familiaridade tende a reduzir a percepção de riscos o que pode levar a uma relativamente baixa frequência de conferência, ou seja, a um baixo nível de envolvimento. Da mesma forma, a imagem, a qualidade percebida e a confiança que uma pessoa tem em relação a uma marca ou estabelecimento onde faz suas compras habituais podem reduzir a percepção de risco e tornar a compra e o consumo mais negligentes (Beneke et al., 2012), e influenciar a frequência da conferência da data de validade dos alimentos.

Pesquisas indicam (Harcar e Karakaya, 2005) que pessoas mais velhas, com nível econômico e escolaridade acima da média, demonstram mais disposição para ler os rótulos dos alimentos e verificar a data de validade. Da mesma forma, as mulheres tendem a dar mais atenção à data de validade, e as pessoas com idade inferior a 35 anos tendem a possuir menor nível de conhecimento sobre segurança alimentar do que as mais velhas. Estes 
dados permitem propor que variáveis, como “idade", "gênero", "renda" e "instrução", possam ser usados como bons preditores deste comportamento, e serem válidos como variáveis para a verificação da existência de cluster entre os consumidores. Por isso, torna-se oportuno investigar a frequência com que a leitura da data de validade é realizada, e sua influência na compra de produtos costumeiros e se o pesquisado sabe como proceder ao encontrar um produto com validade vencida.

\subsubsection{Consumo de produtos com data de validade vencida}

0 consumo de alimentos pode ser fonte de transtornos e doenças alimentares (Grunert, 2005; Griffith, 2006). Baixo conhecimento sobre os riscos de contaminação e a baixa disposição para reconhecer suas decisões e comportamentos são, em grande parte, geradoras de problemas de saúde derivados da alimentação (Bond, Thilmany e Bond, 2008; Cunha et al., 2010; Kennedy et al., 2005). As experiências anteriores podem levar à não-percepção dos riscos, e ao consumo de alimentos que apresentem boa aparência, mas que estejam com a validade vencida (Tsiros e Heilman, 2005).

\subsubsection{Percepção do comportamento de outros significativos}

Além de todos estes aspectos, se faz necessário investigar a percepção a respeito do comportamento dos outros significativos - familiares e amigos - quanto à conferência da data de validade e ao comportamento de consumir alimentos sem conferir a data de validade. Além disso, é importante investigar a percepção que possuem em relação à atenção dada pelos consumidores em geral à validade dos alimentos que compram e consomem, pois, de acordo com a Teoria do Comportamento Planejado, além da influência do conhecimento, o comportamento das pessoas é guiado pelo que elas acreditam sobre quais serão as prováveis consequências sociais de seu comportamento. Assim, suas crenças sobre o que seja o comportamento esperado por parte de terceiros significativos e o apoio ou pressão que acreditam que receberão deles para seus comportamentos na conferência e consumo dos alimentos, influenciam a sua motivação para agir em conformidade às expectativas destes outros. Esta percepção está, ainda, relacionada com o grau de controle que acreditam possuir sobre estas consequências, o que pode facilitar ou dificultar a apresentação dos comportamentos de conferência e consumo destes alimentos (Ajzen, 1991). Em seguida, são apresentadas a metodologia adotada para este estudo e os resultados obtidos nas duas etapas do trabalho.

\section{Metodologia}

Este trabalho foi desenvolvido em dois estágios. No primeiro, coletou-se dados qualitativos sobre 0 conhecimento, atitudes e motivação das pessoas, e dados sobre as decisões de compra e consumo de alimentos e sua relação à data de validade. Para essa coleta foram realizadas entrevistas em profundidade, sendo quatro individuais e duas seções em grupo (cinco e seis participantes). A agenda do debate englobou o conhecimento sobre a data de validade e sua importância na compra e consumo de alimentos, e o comportamento diante de um produto com data de validade vencida, seja na ocasião da compra, seja na ocasião do consumo na residência. Foram feitos registros dos depoimentos e, ao final de cada entrevista, os dados registrados foram apresentados aos entrevistados e aos grupos para avaliação da qualidade dos registros. Aos participantes foi assegurada a confidencialidade e o anonimato de seus depoimentos. Foi feita a análise do conteúdo para se verificar a similaridade dos dados registrados e dos dados coletados, os quais foram usados na construção do questionário aplicado na segunda fase.

No estágio dois, foi realizado um levantamento sobre o conhecimento e comportamento em relação à data de validade dos alimentos. 0 questionário, elaborado a partir de dados colhidos pelo levantamento bibliográfico e no estágio um, foi validado com o objetivo de coletar dados sobre o conhecimento e o comportamento de compra e consumo de alimentos dos participantes. 0 questionário endereçou dois aspectos denominados componentes: [1] “conhecimento", cujas variáveis endereçaram o conhecimento sobre a conservação de alimentos, a data de validade e sua formulação, e os riscos no consumo de alimentos com a data de validade vencida. 0 outro componente, denominado [2] “comportamento', endereçou a investigação sobre a conferência da data de validade na compra e consumo de alimentos, sobre o consumo de produtos com data de validade vencida e sobre a percepção dos participantes sobre o comportamento geral e de outros significativos em relação à data de validade na compra e no consumo de produtos alimentícios. O questionário aplicado foi composto por 19 variáveis para o componente "conhecimento" e por 15 variáveis para o componente "comportamento", tendo sido usada uma escala tipo Likert com cinco pontos, variando de "1 - Discordo plenamente" a “5 Concordo plenamente". A parte final do questionário foi destinada à investigação dos dados demográficos de cada respondente.

A amostra empregada foi não-probabilística de conveniência por facilitar a localização de respondentes e por ser de baixo custo (Aaker, Kumar, Day e Leone, 2009). Parte dela foi composta por pessoas que compareceram espontaneamente em uma agência de empregos e que aceitaram responder ao questionário - amostra de fluxo - e outra parte foi acessada em uma instituição de formação profissional. A todos foi informado o objetivo da pesquisa e solicitada a colaboração, sendo aplicado o questionário a todos que voluntariamente se dispuseram a participar da pesquisa.

Os dados foram submetidos à análise fatorial exploratória - Análise dos Componentes Principais com a rotação Varimax - para a obtenção das cargas fatoriais e 
à análise confiabilidade total (alpha de Cronbach). Foram também submetidos ao teste de igualdade de médias (Teste t e ANOVA) para a análise da correlação entre os fatores identificados para o componente "conhecimento" e para o componente "comportamento" com o objetivo de se verificar a significância estatística das proposições estabelecidas, e para se verificar a ocorrência de diferença entre as médias dos agrupamentos especificados, considerando-se as variáveis categóricas: idade, gênero, renda e instrução. Para utilizar estas variáveis, elas foram codificadas de tal modo que pudessem representar uma escala métrica.

\section{Análise dos resultados obtidos}

A seguir são apresentados os resultados obtidos no estágio um - as entrevistas individuais e em grupo, - e os resultados obtidos no estágio dois - levantamento sobre o conhecimento e comportamento em relação à data de validade dos alimentos.

\subsection{Resultados do estágio um: entrevistas individuais e em grupo}

Um total de 12 pessoas participou das entrevistas em profundidade, tendo sido realizadas quatro entrevistas individuais e duas seções de entrevista em grupo. Os resultados obtidos neste estágio permitiram a constatação de que as pessoas apresentam diferenças significativas tanto em relação ao conhecimento sobre a data de validade, como sobre a importância atribuída a ela no processo de compra e consumo de produtos alimentícios. A análise dos depoimentos e registros permitiram as seguintes constatações:

- Conhecimento sobre a data de validade: de modo geral, os entrevistados estão cientes de sua existência impressa nas embalagens, mas não possuem conhecimento específico sobre como elas são determinadas. Esta falta de conhecimento levou alguns deles a questionarem a veracidade da data de validade e mesmo a considerá-la apenas como uma data de referência. Como disse um dos entrevistados (masculino, 32 anos, segundo grau)," [...] de modo geral, o que eu observo é que os alimentos continuam bons para o consumo mesmo depois do vencimento da data de validade". (sic) Outro complementou (feminino, 58 anos, superior): "[...] é o caso do leite não pasteurizado. Sabemos que ele está bom quando a gente ferve ou quando ele fica coalhado na garrafa e isso nem sempre tem relação com a data de validade." (sic).

- Importância na compra e consumo de alimentos: todos disseram saber da importância da data de validade. Apesar de acharem importante, nem todos dão a atenção necessária ou leem a data de validade com o cuidado requerido quando da compra desses produtos. Outro entrevistado (feminino, 27 anos, segundo grau) referiuse aos alimentos processados nos supermercados: "Quem garante que a data colocada naquele pedaço de queijo é a que estava na embalagem original? Será que tem como conferir?" (sic). Para outro entrevistado (masculino, 62 anos, superior,), a questão da data de validade dos alimentos é um critério decisivo tanto na compra, como no consumo: "Ninguém deve comprar e nem consumir com a data vencida. É correr risco desnecessário!" (sic).

- Comportamento na compra e consumo de alimentos: observação de um dos entrevistados (masculino, 64 anos, primeiro graul apontou a existência de dissonância entre o que é dito e o que é feito em relação à data de validade: "muitos falam que nem compram e nem consomem alimentos com a data de validade vencida. Falam isso porque têm medo de ser recriminados. Na verdade, não olham nada disso quando compram ou comem estes alimentos, sem se importar com a data de validade" (sic). Outro entrevistado (feminino, 42 anos, segundo graul foi coerente com esta afirmação quando disse "a gente sempre faz as compras correndo e, na maior parte das vezes, nem me lembro da data de validade." (sic) e na entrevista em grupo, outro participante (masculino, 33 anos, superior) "a gente compra sempre o mesmo produto e é tudo meio automático; a gente nem se lembra de conferir a data de validade e quando chega em casa a gente coloca na geladeira e pronto". (sic).

Mas também há relatos que informam que, além de considerarem importante, fazem a conferência da data de validade como procedimento usual na compra de alimentos (masculino, 64 anos, superior): "Antes de colocar um produto alimentício no carrinho eu confiro a data de validade; tive uma experiência desagradável há uns cinco anos: ao abrir a embalagem de um queijo e ele estava cheirando mal. Aí conferi a data de validade e constatei que a validade venceria no dia seguinte. A partir desta data, confiro a data de tudo!" (sic).

Os dados obtidos denotam, também, que apesar de considerarem a data de validade uma orientação importante em suas atitudes e comportamentos em relação à compra e consumo de alimentos, nem sempre a levam em consideração quando do consumo em suas residências. Isto pode ser observado no depoimento feito por outro entrevistado (feminino, 58 anos, superior): "no dia-a-dia, como nunca tivemos problema, a gente nem se lembra de conferir a data de validade da margarina e do requeijão que a gente coloca na mesa para o café da manhã" (sic). Mas há também um registro de um depoimento em sentido contrário lfeminino, 32 anos, segundo graul: "desafio vocês a revistarem minha geladeira e encontrarem um produto com validade vencida. A saúde do meu filho é muito importante e eu não quero correr nenhum risco. Venceu, jogo fora sem dó!" (sic).

Estes resultados qualitativos permitem a constatação de que as pessoas entrevistadas estão cientes a existência da data de validade impressa nas embalagens, mas apresentam diferenças significativas tanto em relação ao conhecimento sobre a data de validade 
quanto a importância atribuída no processo de compra e consumo de produtos alimentícios. De um lado estão os que possuem conhecimento elevado sobre a data de validade dos alimentos, sobre como ela é determinada; de outro, há os que não têm informação sobre este processo, sua influência sobre a qualidade dos alimentos, e os riscos decorrentes de seu consumo, como no caso dos que declararam ter consumido produtos com data de validade vencida e nunca tirem tido problemas.

Da mesma forma, quando considerada a importância dada à data de validade quando da compra e consumo dos alimentos, verificam-se comportamentos bastante diversos. Uma parte deles sempre confere a data de validade: seja na compra ou no consumo. Outra parte relega este aspecto a um plano inferior, e se apoia em sua história pessoal, sua observação, e análise do produto como base para considerar o produto com validade vencida como adequado para o consumo ou não, e para descartá-lo e jogá-lo fora. Isto denota que estes consumidores podem não achar que a data de validade seja uma orientação importante para suas atitudes e comportamentos em relação, não só ao processo de compra, mas, e, talvez, principalmente, sobre os hábitos de consumo de produtos alimentícios com data de validade vencida e que, por exemplo, se encontram dentro da geladeira ou do freezer doméstico.

Esta constatação também é importante por ser um assunto relacionado à saúde pública e às despesas com o tratamento de pessoas com problemas contraídos pelo consumo de produtos com data de validade vencida. Isto é um fato importante, pois é significativo o número de pessoas (em torno de um terço da população) que já teve problemas de saúde por causa de intoxicação alimentar devido ao consu validade vencida (Moreira, 2009).

4.2 Resultados do estágio dois: levantamento sobre o conhecimento e o comportamento em relação à data de validade dos alimentos

A seguir são apresentados os resultados obtidos no levantamento sobre o conhecimento e comportamento em relação à data de validade dos alimentos.

\subsubsection{Características da amostra}

0 levantamento envolveu 199 participantes sendo $54,3 \%$ homens e 45,7\% mulheres. A Tabela 2 apresenta os dados dos participantes deste estágio em relação a gênero, idade, instrução e renda.

\subsubsection{Resultados do PCA}

A Análise dos Componentes Principais foi empregada para identificar o número de fatores ou dimensões básicas que melhor representam as correlações observadas entre o conjunto inicial de variáveis que compuseram o questionário (Hayes, 2001; Hair, Black, Babin Anderson e Tathan, 1998), sendo reunidas as que estão altamente correlacionadas entre si, compondo um único fator. Esta análise, foi feita separadamente para os dois objetivos da pesquisa: conhecimento e atitudes em relação à data de validade; e o comportamento de compra e consumo de alimentos e sua relação com a data de validade.

0 resultado da rotação Varimax e da normalização Kaiser possibilitaram a simplificação e a interpretação dos fatores; as cargas fatoriais foram usadas para identificar quais itens do questionário compõem cada fator, e para interpretar cada fator identificado (Hair et al., 1998; Hayes, 2001). Todas as variáveis com carga fatorial igual ou superior a 0,35 foram conservadas para compor o questionário. A análise dos componentes principais usou como valor de corte o Eigenvalue 1,0 (Hair et al., 1998) e os coeficientes de confiabilidade lalfa de Cronbach) computados para conhecimento e atitudes, e para o comportamento de compra e consumo, mostraram adequado nível de consistência interna (Cronbach, 1951; Hair et al., 1998). O limite mínimo geralmente aceito é 0,70 , podendo ser aceito um valor de 0,60 em estudos exploratórios (Hair et al., 1998).

\subsubsection{Conhecimento em relação à data de validade}

A análise dos itens que compuseram o questionário sobre conhecimento, motivação e a atitude em relação à data de validade indicou a existência de três fatores: conhecimento sobre a conservação de alimentos, conhecimento do consumidor sobre a data de validade e conhecimento dos riscos na compra e consumo de alimentos com a data de validade vencida.

- Conhecimento sobre a conservação de alimentos: este fator inclui a relação da data de validade com o congelamento dos alimentos, sua armazenagem na geladeira, a necessidade de data de validade, a relação de seu vencimento com a deterioração e adequação ao consumo, e a finalidade dos testes para a determinação da data de validade e sua relação com a estabilidade dos produtos.

- Conhecimento sobre a data de validade: este fator englobou os conhecimentos sobre os procedimentos para a determinação da data de validade, sobre a legislação pertinente e sobre os direitos do consumidor em relação a ela. Englobou também conhecimentos sobre a relação da data de validade com a conservação da capacidade alimentícia e com sua adequação ao consumo, as condições ambientais necessárias para a conservação, e sobre a capacidade de avaliar se um alimento está ou não deteriorado ou estragado, quando ele está na gôndola do supermercado.

- Conhecimento dos riscos e perigos no consumo de alimentos com a data de validade vencida: englobou a data de validade como proteção ao consumidor, o risco à saúde causado pelo consumo de alimentos com data de validade vencida mas sem que apresente sinais de deterioração, s sua experiência no consumo deste tipo de produtos alimentícios, e a relação entre o consumo pelos animais com o consumo humano. Medida pelo 
alfa de Cronbach, a confiabilidade deste questionário $(0,83)$ indica que ele é adequado para os propósitos da pesquisa (Tabela 3 ).

\subsubsection{Comportamento de compra e consumo e sua relação com a data de validade}

A análise dos itens do componente "comportamento de compra" e "consumo" e sua relação com a data de validade làs vezes designado como questionário sobre comportamentol indicou a ocorrência de três fatores: i) verificação e conferência da data de validade, ii) consumo de alimentos com a data de validade vencida e iii) percepção sobre o comportamento das outras pessoas em relação à compra e consumo de alimentos, com data de validade vencida.

- Verificação e conferência da data de validade: este fator incluiu a conferência da data de validade dos alimentos tanto na compra quanto no consumo de alimentos.
Englobou a frequência com que a leitura da data de validade é realzada, a influência desta data na compra de produtos costumeiros (compra de baixo envolvimento), e se o participante sabe o que fazer quando encontra um produto com validade vencida.

- Consumo de produtos com a data de validade vencida: englobou o consumo de alimentos com data de validade vencida com boa aparência, a percepção de riscos do consumo deste tipo de produto e o aproveitamento das promoções em função da proximidade da data de vencimento de produtos alimentícios.

- Percepção sobre o comportamento dos outros: englobou a percepção do comportamento de outras pessoas do relacionamento familiar e de amizade e o conceito que o participante possui sobre o comportamento das pessoas em geral.

Medida pelo alfa de Cronbach, a confiabilidade deste questionário $(a=0,8286)$ indica que ele é adequado para os propósitos da pesquisa (Tabela 4).

Tabela 2. Características dos participantes

\begin{tabular}{|c|c|c|c|c|c|c|c|}
\hline Gênero & $\%$ & Idade & $\%$ & Escolaridade & $\%$ & Renda (R\$) & $\%$ \\
\hline Masculino & 54,3 & Até 20 & 16,8 & $1^{\circ} \mathrm{Grau}$ incompleto & 2,7 & Até 500 & 3,7 \\
\hline \multirow[t]{6}{*}{ Feminino } & 45,7 & 21 a 25 & 48,2 & $1^{\circ} \mathrm{Grau}$ Completo & 2,7 & $501-1000$ & 31,0 \\
\hline & & 26 a 30 & 24,6 & $2^{\circ} \mathrm{Grau}$ Incompleto & 3,2 & 1001 a 1500 & 25,1 \\
\hline & & 31 a 35 & 12,0 & $2^{\circ} \mathrm{Grau}$ Completo & 31,2 & 1501 a 2000 & 19,8 \\
\hline & & $36+$ & 15,2 & Superior Incompleto & 52,2 & 2001 a 2500 & 6,4 \\
\hline & & & & Superior & 10,2 & 2501 a 3000 & 5,9 \\
\hline & & & & Pós Graduação & 6,5 & $3001-+$ & 8,0 \\
\hline $\mathrm{N}$ & 199 & $\mathrm{~N}$ & 196 & $\mathrm{~N}$ & 196 & $\mathrm{~N}$ & 187 \\
\hline
\end{tabular}

Fonte: elaboração própria.

Tabela 3. Conhecimento dos participantes sobre a data de validade - cargas fatoriais

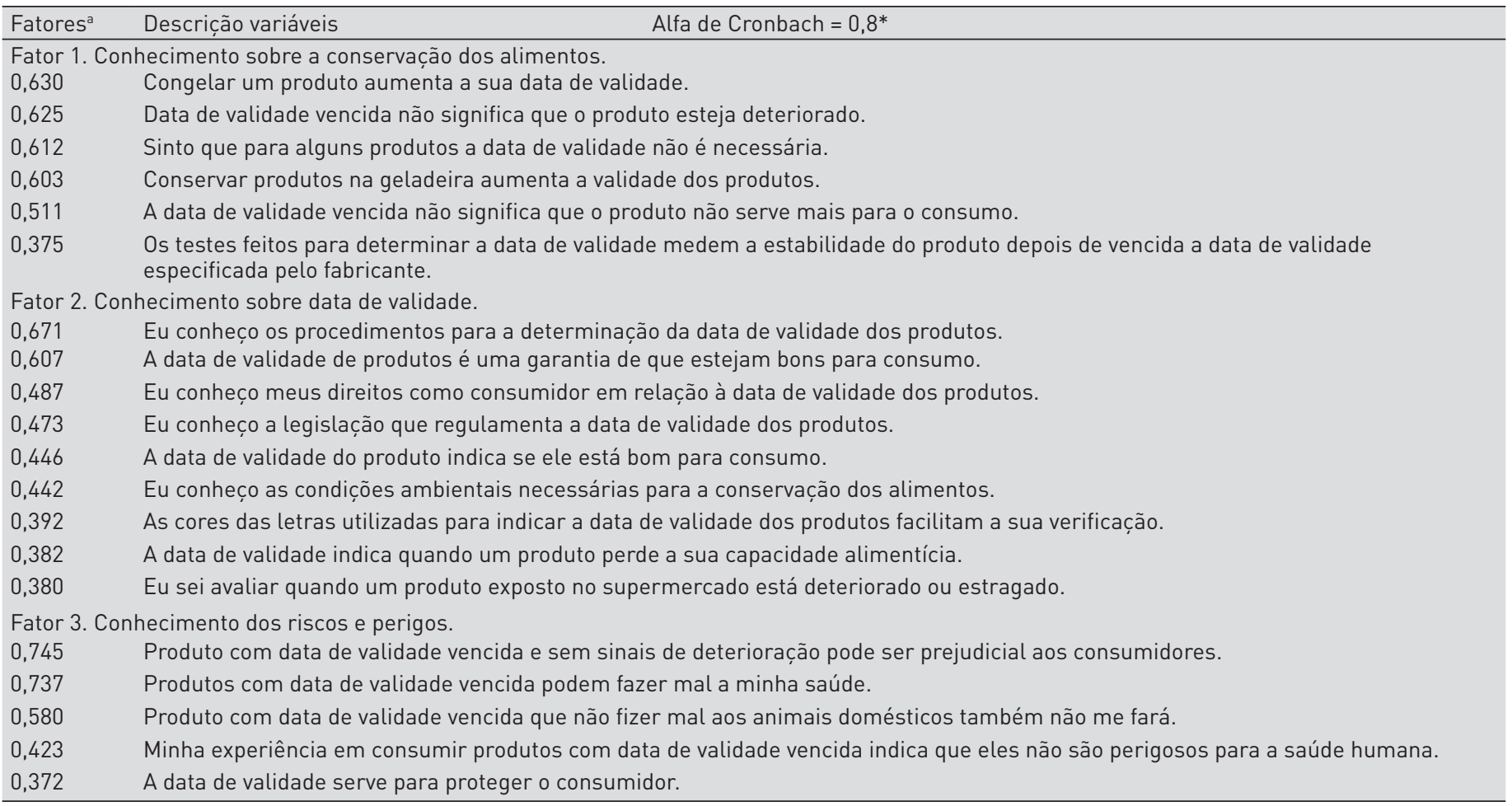

Método de Extração: Análise dos Componentes Principais. Método de Rotação: Varimax com Normalização Kaiser. a. Rotação convergida em 5 iterações ns. *O Alfa de Cronbach $(0,83)$ refere-se a análise dos três fatores identificados.

Fonte: elaboração própria. 
Tabela 4. Comportamento de compra e consumo de alimentos com data de validade vencida

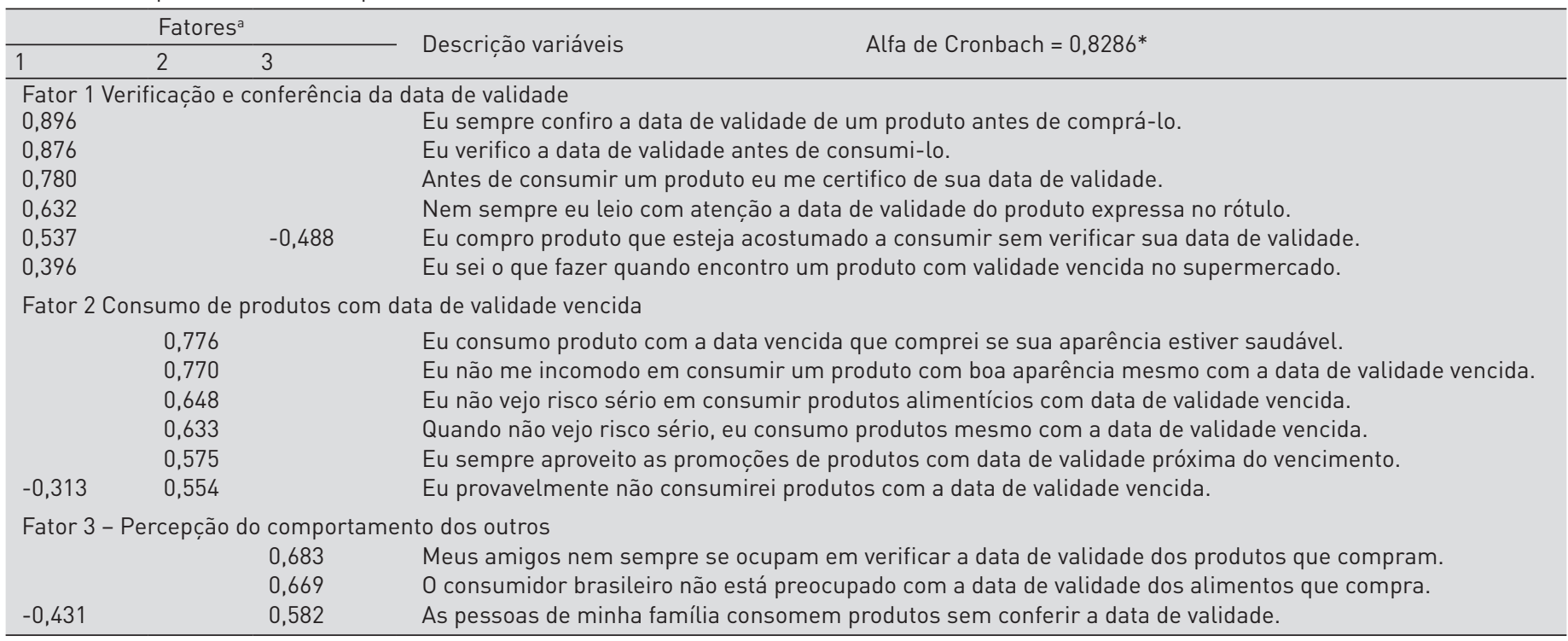

Método de Extração: Análise dos componentes principais. Método de Rotação: Varimax com Normalização Kaiser. a. Rotação convergida em 5 iterações. ${ }^{*}$ Alfa de Cronbach $=0,8286$ refere-se a análise dos três fatores identificados.

Fonté: elaboração própria.

Tabela 5. Teste para diferença entre as médias para o componente conhecimento

\begin{tabular}{|c|c|c|c|c|c|c|c|c|c|c|c|c|c|}
\hline \multicolumn{14}{|c|}{ Componente 1 - Conhecimento } \\
\hline \multirow{2}{*}{ Variável } & & \multicolumn{5}{|c|}{ Conservação } & \multicolumn{3}{|c|}{ Data validade } & \multicolumn{4}{|c|}{ Riscos } \\
\hline & & $\mathrm{N}$ & Média & $\mathrm{DP}$ & p-valor & $\mathrm{N}$ & Média & $\mathrm{DP}$ & p-valor & $\mathrm{N}$ & Média & $\mathrm{DP}$ & p-valor \\
\hline \multirow[t]{2}{*}{ Gênero } & Fem. & 98 & 0,048 & 1,023 & & 98 & 0,124 & 1,029 & & 98 & $-0,024$ & 0,994 & \\
\hline & Masc. & 83 & $-0,045$ & 1,017 & 0,543 & 83 & $-0,15$ & $0, .958$ & 0,067 & 83 & 0,002 & 1,034 & 0,866 \\
\hline \multirow[t]{5}{*}{ Idade } & $\geqslant 20$ anos & 31 & 0,125 & 1,265 & & 31 & 0,1 & 1,257 & & 31 & $-0,139$ & 0,786 & \\
\hline & $21-25$ & 60 & 0,022 & 0,861 & & 60 & 0,082 & 0,87 & & 60 & 0,023 & 1,055 & \\
\hline & $26-30$ & 46 & $-0,153$ & 0,953 & 0,172 & 46 & 0,163 & 0,969 & 0,202 & 46 & 0,079 & 1,103 & 0,742 \\
\hline & $31-35$ & 23 & 0,38 & 1,001 & & 23 & $-0,29$ & 1,035 & & 23 & 0,147 & 0,882 & \\
\hline & $\leqslant 36$ anos & 28 & $-0,234$ & 1,013 & & 28 & $-0,277$ & 0,953 & & 28 & $-0,145$ & 1,057 & \\
\hline \multirow[t]{2}{*}{ Renda } & $\geqslant R \$ 1500$ & 110 & $-0,058$ & 1,037 & & 110 & $-0,012$ & 0,96 & & 110 & -0.018 & 0,947 & \\
\hline & $\leqslant R \$ 1501$ & 74 & 0,112 & 0,973 & 0,265 & 74 & 0,006 & 1,062 & 0,904 & 74 & $-0,011$ & 1,085 & 0,963 \\
\hline \multirow[t]{2}{*}{ Instrução } & $>2^{\circ} \mathrm{Grau}$ & 57 & $-0,279$ & 0,878 & & 57 & $0, .816$ & 0,443 & & 57 & 0,018 & 0,935 & \\
\hline & $\leqslant 2^{\circ} \mathrm{Grau}$ & 125 & 0,136 & 1,043 & 0,006 & 125 & 1,012 & $-0,219$ & 0,000 & 125 & $-0,026$ & 1,041 & 0,786 \\
\hline
\end{tabular}

Fonte: elaboração própria.

\subsection{Diferenciação entre os grupos de participantes}

Os resultados para os componentes "conhecimento e consumo de alimentos" foram submetidos ao Teste t de Student / ANOVA para se verificar a ocorrência de diferença de médias entre os grupos especificados pelas: idade, gênero, renda e escolaridade (Tabela 5).

\subsubsection{Componente conhecimento}

Os dados encontrados parecem indicar, conforme parecem indicar as médias obtidas, em relação ao conhecimento sobre conservação, as mulheres, mais do que os homens, as pessoas com idade na faixa de 32 a 35 anos, com renda $=\mathrm{R} \$ 1.500,00$ e com instrução $>2^{\circ} \mathrm{Grau}$ - $=2^{\circ} \mathrm{Grau}$, que haja uma tendência, não confirmada, a demonstrarem um pouco mais de conhecimento sobre a conservação de alimentos. Em relação à data de validade, há indicativos, não confirmados, de que as mulheres, mais do que os homens, as pessoas com idade $=30$ anos, com renda $-=R \$ 1.500,00$ e com instrução $=2^{\circ} \mathrm{Grau}$, parecem possuir um pouco mais de conhecimento em relação a ela, da mesma forma, como parecem indicar as médias obtidas. Quando se trata do conhecimento sobre os riscos, pode-se depreender, a partir das médias obtidas, em relação aos participantes do levantamento, os homens, mais do que as mulheres, as pessoas com idade entre 21 e 35 anos e com instrução abaixo do segundo grau, que haja uma leve tendência, não confirmada, a demonstrarem um nível maior conhecimento sobre os riscos decorrentes do consumo de alimentos com a data de validade vencida. Estes dados, apesar de poderem ser deduzidos a partir das médias obtidas, são ilustrativos e não possuem significado estatístico.

Os dados obtidos para este componente foram submetidos ao teste de igualdade de médias para se verificar a ocorrência de diferença entre os grupos especificados para as variáveis idade, gênero, renda e escolaridade. De acordo com os resultados obtidos, para o componente conhecimento, as variáveis gênero, idade e renda não produziram diferença significativa entre as médias em nenhum dos fatores identificados, não se mostrando, nesta amostra, serem bons filtros para identificar 
diferenças entre os perfis dos consumidores, não se constituindo bases adequadas para a segmentação do mercado.

A avaliação da adequação destas variáveis como filtros para a segmentação de mercado, indicou que apenas quando se considera o nível de instrução, os dados mostram que há diferença significativa para os fatores 1 - conhecimento sobre a conservação de alimentos - o $p$-value $=0,006=0,05$, e para o fator 2 - conhecimento sobre a data de validade -0 -value $=0,000=0,05$ quando se considera dois grupos: $>2^{\circ} \mathrm{Grau}-=2^{\circ} \mathrm{Grau}$. Isto é um indicador significativo para considerar que, com $95 \%$ de confiança, que a escolaridade, assim segmentada, pode se constituir em uma variável adequada para se segmentar os consumidores de alimentos acerca do conhecimento sobre conservação e sobre a data de validade.

Os dados indicam também que não foram encontradas diferenças significativas para o fator conhecimento sobre os riscos e perigos, o que indica que estas variáveis gênero, idade, renda e escolaridade não se constituem em filtros adequados para a segmentação de mercado quando se considera este fator.

\subsubsection{Componente comportamento}

Os dados da Tabela 6 indicam que, em relação ao componente comportamento quando da compra e consumo de alimentos, as mulheres, mais do que os homens, as pessoas com idade $=20$ anos e com idade entre 31 e 35 anos indicaram fazer a conferência da data de validade com maior frequência que os outros pesquisados.

Em relação ao comportamento de compra e consumo de alimentos com data de validade vencida, os dados indicam que os homens, mais do que as mulheres, as pessoas com idade $=20$ anos e com instrução $=2^{\circ} \mathrm{Grau}$ apresentam maior tendência a não consumirem alimentos com data de validade vencida. Quanto à percepção do comportamento de outros significativos (fator 3), de acordo com os dados da Tabela 6, os homens, mais do que as mulheres, as pessoas com idade $=30$ anos, com renda $=R \$ 1.500,00$ e com instrução $=2^{\circ}$ Grau tendem a indicar que seus amigos nem sempre se preocupam em conferir a data de validade. Em relação aos seus familiares, estes participantes indicaram que, em grande parte, eles consomem alimentos com data de validade vencida e que, o consumidor brasileiro, em boa parte, não está preocupado com a data de validade dos alimentos que compram.

Os resultados para o componente Comportamento - conferência e consumo de alimentos com data de validade vencida - foram submetidos ao teste igualdade de médias (t de Student e ANOVA) para se verificar a ocorrência de diferença entre os grupos especificados para as variáveis: idade, gênero, renda e escolaridade. Esta análise apontou que existe diferença apenas para duas variáveis: Renda e Instrução. Para a variável renda, houve diferença estatisticamente significativa para o fator 2 - Consumo de produtos com a data de validade vencida ( $p$-value $=0,047=0,05)$ - apenas quando se segmenta os pesquisados em dois grupos: renda >R\$ 1.500,00 $=\mathrm{R} \$ 1.501,00$.

Da mesma forma, a variável escolaridade também apresentou diferenças estatisticamente significativas quando se separa os participantes em dois grupos: $>2^{\circ}$ Grau - $=2^{\circ} \mathrm{Grau}$. Esta diferença é significativa tanto para o fator conferência da data de validade ( $p$-value=0,004= $0,01)$ quanto para o fator compra e consumo de alimentos com data de validade vencida ( $p$-value $=0,10=0,01)$.

\subsection{Análise das proposições}

Para verificar as proposições, os dados obtidos foram submetidos à Análise Fatorial utilizando a Análise dos Componentes Principais com a rotação Varimax para a obtenção das cargas fatoriais. Para os dois componentes foram encontrados três fatores, todos com Eigenvalue superiores a 1 (Tabela 4 e Tabela 5). Estes resultados foram submetidos ao Teste $t$ e ANOVA para verificar se as proposições feitas sobre as relações entre os componentes "conhecimento" e “comportamento" são estatisticamente significativas (Tabela 7).

Em relação à proposição $P 1$, os dados da Tabela 6 não indicam evidências de relação significativa entre o conhecimento sobre a conservação de alimentos e - comportamento de conferência da data de validade dos alimentos, quando da compra e do consumo de alimentos ( $r=0,032$ / $p=0,668$ - não significativo) para os pesquisados. Em relação à proposição $P 2$, a análise dos dados (Tabela 6) indica - confirma - que, para os participantes do levantamento, há relação significativa entre o conhecimento sobre conservação de alimentos e o comportamento de consumo de alimentos - $r=0,565$ ( $p<0,001$ - com significância estatística). Em relação à proposição P3, os dados encontrados evidenciam a existência de relação significativa entre o conhecimento sobre a data de validade e sua conferência ( $r=0,332$ / ( $p<0,001$ - com significância estatística).

A proposição $\mathrm{P} 4$, referente à relação entre o nível de conhecimento sobre a data de validade e sua influência sobre o comportamento de consumo de alimentos com a data de validade vencida foi rejeitada, uma vez que os dados encontrados evidenciaram que não existe relação estatisticamente significativa para a amostra de consumidores que participaram do levantamento ( $r=-0,026$ ( $p=0,719$ - não significativo). Isto pode estar relacionado ao fato de que informações sobre a data de validade, não sejam algo de domínio das pessoas e que, de modo geral, a data de validade e suas implicações para o consumo de alimentos, para muitos produtos, não seja considerada uma informação relevante para as suas decisões de consumo destes alimentos. Além disso, de modo geral, a experiência das pessoas com o consumo de alimentos de uma maneira mais descuidada não reporta experiências de contaminação e de problemas de saúde devido à sua ingestão. Mesmo em casos positivos de contaminação, muitas vezes os problemas de saúde resultantes não causaram transtornos graves a ponto de realçar a importância da data de validade. 
Conforme mostram os dados da Tabela 6, não existe relação estatisticamente significativa entre (P5) o conhecimento dos riscos associados à data de validade, e a frequência com que esta data é conferida pelos participantes deste levantamento $(r=-0,057 / p=0,437$ - não significativol. Isto parece estar relacionado ao fato de que os participantes do levantamento depositam maior confiança em sua avaliação sobre a aparência do alimento que estão comprando ou consumindo, do que aos riscos dos quais a data de validade possa ser uma indicação confiável. Pode também ter relação com o fato de que, em geral, as pessoas tendem a dar mais valor e atenção à gravidade das ocorrências do que ao risco de se contaminar e ao fato de que, mesmo em caso de contaminação, os problemas de saúde resultantes não causaram transtornos graves a ponto de realçar a necessidade de se ater aos riscos de contaminação.

Os dados obtidos sobre a relação entre (P6) o nível de conhecimento sobre os riscos e o comportamento de compra e consumo de alimentos indicam que, para esta amostra de pesquisados, o conhecimento sobre os riscos influencia a compra e o consumo de alimentos com data de validade vencida $(r=-0,426 / p<0,001$ - com significância estatístical. Mas, quando se compara estes dados com os obtidos sobre a relação entre o conhecimento sobre os riscos e a conferência da data de validade, surge a dúvida sobre se estas respostas correspondem à realidade de consumo, ou se são apenas respostas baseadas em suposições sobre qual deveria ser a resposta socialmente mais adequada para esta proposição.

Tabela 6. Teste para diferença entre as médias para o componente comportamento

\begin{tabular}{|c|c|c|c|c|c|c|c|c|c|c|c|c|c|}
\hline \multicolumn{14}{|c|}{ Componente 2 - compra e consumo } \\
\hline \multirow{2}{*}{ Variável } & & \multicolumn{5}{|c|}{ Conferência } & \multicolumn{3}{|c|}{ Compra e consumo } & \multicolumn{4}{|c|}{ Percepção outros } \\
\hline & & $\mathrm{N}$ & média & DP & $\mathrm{p}$-valor & $\mathrm{N}$ & média & DP & $\mathrm{p}$-valor & $\mathrm{N}$ & média & DP & $p$-valor \\
\hline \multirow[t]{2}{*}{ Gênero } & Fem. & 96 & 0,068 & 1,001 & & 96 & $-0,059$ & 0,996 & & 96 & $-0,036$ & 1,016 & \\
\hline & Masc. & 83 & $-0,039$ & 0,985 & 0,471 & 83 & 0,052 & 1,043 & 0,469 & 83 & 0,016 & 1,015 & 0,73 \\
\hline \multirow[t]{3}{*}{ Idade } & $\geqslant 20$ anos & 31 & 0,038 & 1,172 & & 31 & 0,22 & 1,263 & & 31 & 0,138 & 0,949 & \\
\hline & $21-25$ & 59 & $-0,013$ & 0,91 & & 59 & 0,012 & 1,052 & & 59 & 0,104 & 0,957 & \\
\hline & $\leqslant 36$ anos & 28 & 0,264 & 0,907 & & 28 & $-0,005$ & 0,778 & & 28 & $-0,422$ & 1,106 & \\
\hline \multirow[t]{2}{*}{ Renda } & $\geqslant R \$ 1500$ & 110 & $-0,001$ & 0,969 & & 110 & $-0,128$ & 0,958 & & 110 & 0,017 & 0,894 & \\
\hline & $\leqslant R \$ 1501$ & 74 & 0,061 & 1,044 & 0,684 & 74 & 0,175 & 1,068 & 0,047 & 74 & 0,004 & 1,154 & 0,933 \\
\hline \multirow[t]{2}{*}{ Instrução } & $>2^{\circ} \mathrm{Grau}$ & 56 & 0,294 & 0,729 & & 56 & $-0,272$ & 0,784 & & 56 & $-0,177$ & 0,883 & \\
\hline & $\leqslant 2^{\circ} \mathrm{Grau}$ & 124 & $-0,112$ & 1,088 & 0,004 & 124 & 0,103 & 1,082 & 0,01 & 124 & 0,076 & 1,047 & 0,117 \\
\hline
\end{tabular}

Fonte: elaboração própria.

Tabela 7. Correlação entre o conhecimento e o comportamento

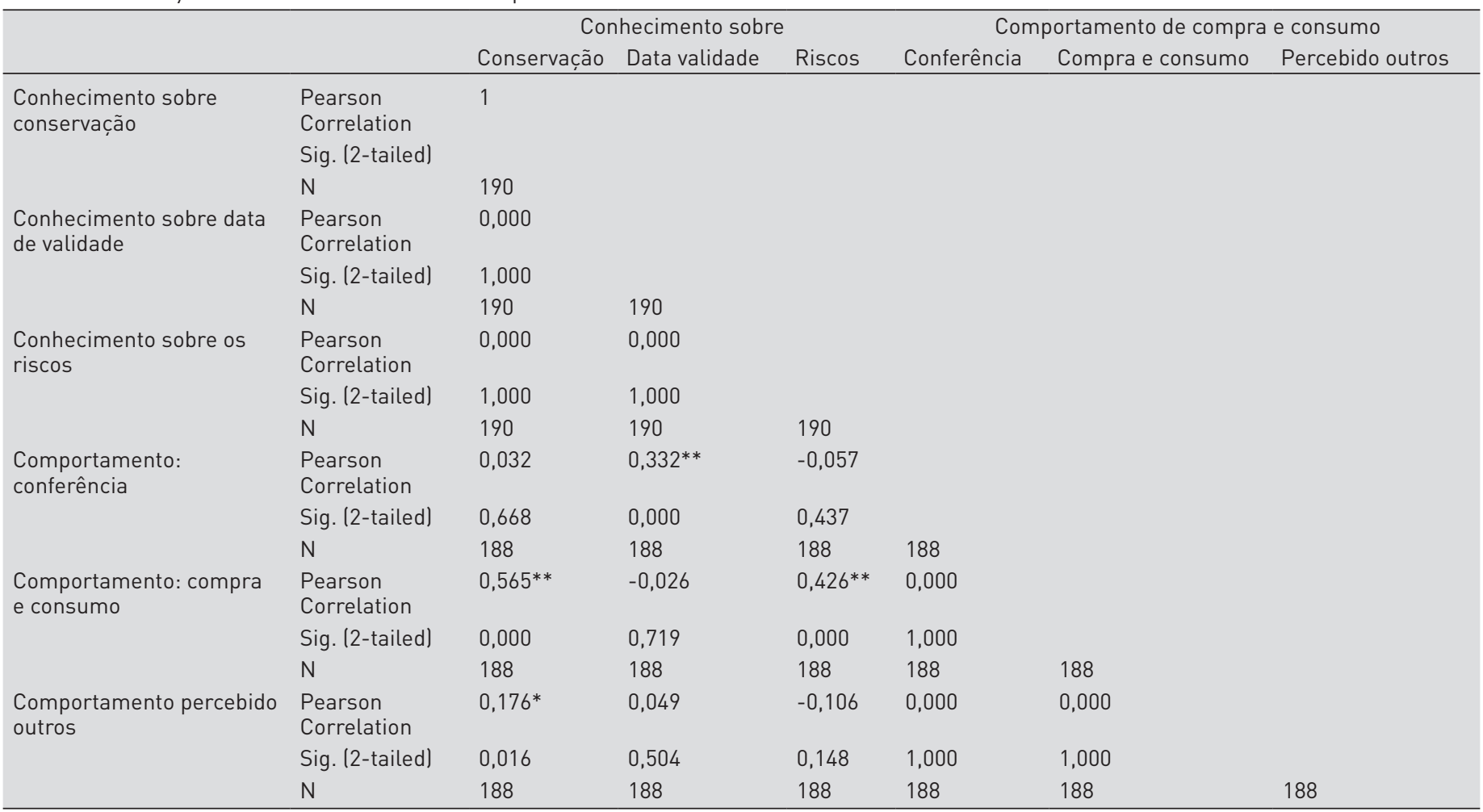

**Correlação é significativa no nível 0.01(cauda dupla). * Correlação é significativa no nível 0.05 (cauda dupla).

Fonte: elaboração própria. 


\section{Conclusão}

0 presente estudo teve como objetivo investigar o nível de conhecimento sobre questões relativas à data de validade dos alimentos e sua relação com o comportamento de compra e consumo de alimentos. Estes tópicos foram considerados componentes e foram avaliados por meio da análise fatorial, sendo identificados três fatores para o componente "conhecimento" - conservação de alimentos, data de validade e riscos no consumo de alimentos com data de validade vencida, e três fatores para o componente "comportamento de compra e consumo de alimentos" - conferência da data de validade, consumo de alimentos com data de validade vencida, a percepção dos participantes sobre o comportamento de compra e consumo de outros significativos - amigos e familiares -, e a percepção do comportamento geral dos brasileiros.

Os dados obtidos foram utilizados para se proceder ao cruzamento com as variáveis categóricas: gênero, idade, renda e instrução, havendo indicações de que apenas a variável "instrução" (>2 $2^{\circ}$ Grau - $=2^{\circ}$ Grau) seja adequada para segmentar os consumidores participantes do levantamento, mas apenas quando se consideram, no componente "conhecimento", os fatores conhecimento sobre conservação dos alimentos, e sobre a data de validade.

Já para o componente "compra e consumo de alimentos com data de validade vencida", os dados indicam que para a variável "Renda", houve diferença estatisticamente significativa para o fator 2 - consumo de produtos com a data de validade vencida - apenas quando se segmenta os pesquisados em dois grupos: renda > $\mathrm{R} \$ 1.500,00-=\mathrm{R} \$ 1.501,00$. Da mesma forma, a variável "Escolaridade" também apresentou indícios de diferenças estatisticamente significativas quando se separa os participantes em dois grupos: $>2^{\circ} \mathrm{Grau}-=2^{\circ}$ Grau, para os fatores conferência da data de validade e compra e consumo de alimentos com data de validade vencida.

Em relação às proposições feitas, os dados obtidos para os participantes do levantamento são indicativos de que pode não haver correlação entre o conhecimento sobre conservação de alimentos e a conferência da data de validade na compra e consumo de alimentos. Já para a relação entre o conhecimento sobre conservação de alimentos e o comportamento de consumo de alimentos, há evidências de que esta relação seja significativa. A análise da relação entre conhecimento sobre a data de validade e o comportamento de consumo de alimentos mostrou-se significativa, numa indicação de que o conhecimento sobre a data de validade influencia o consumo de alimentos, mas não influencia o consumo de alimentos com data de validade vencida. De acordo com os dados do levantamento, para muitos deles, a data de validade não é considerada relevante e eles parecem dar mais atenção às suas experiências para a tomada desta decisão.

Os dados também não indicaram relação significativa entre o conhecimento sobre riscos associados à data de validade, e a sua conferência quando da compra e consumo de alimento, uma vez que parecem basear suas decisões mais na aparência do alimento e em sua experiência pessoal, do que nos riscos que validade vencida possa indicar. Já sobre a relação entre o nível de conhecimento sobre os riscos e o comportamento de compra e consumo de alimentos, os dados parecem indicar a ocorrência de indícios de que, para esta amostra de pesquisados, o conhecimento sobre os riscos influencia a compra e o consumo de alimentos com data de validade vencida.

Os resultados encontrados apontam na direção da necessidade de as agências governamentais e empresas desenvolverem e implementarem programas educacionais que objetivem informar, esclarecer dúvidas e mudar equívocos; orientar as decisões na compra e consumo de alimentos, dado que, por exemplo, a data de validade parece não ser considerada relevante e eles parecem dar mais atenção às suas experiências e se valerem mais da aparência dos alimentos do que dos riscos que validade vencida possa indicar para a tomada desta decisão. Isto, certamente, poderá gerar maiores benefícios para os consumidores e, até certo ponto, reduzir a incidência de problemas de saúde causados pela ingestão de alimentos e a minimização dos sofrimentos e transtornos individuais e familiares, perdas sociais, econômicas e de produtividade que este consumo inadequado possa causar.

Indicam, também, a necessidade da adoção de ações educacionais nos pontos de venda, que vão para além dos cartazes que indicam que o "consumidor terá direito a outro produto grátis se encontrar produto com data de validade vencida", gerando oportunidades para, por exemplo, examinar produtos com validade vencida ao microscópio para se constatar a existência de microorganismos em proliferação em alimentos com data de validade vencida. Pode, também, auxiliar os distribuidores em suas políticas de promoção dos produtos que estejam com sua data de validade próxima ao vencimento e assim evitar ou minimizar perdas com estes alimentos e propiciar oportunidade de consumo para consumidores que, de outra forma, não teriam acesso ao consumo dos produtos em promoção.

Uma das limitações deste estudo é a sua amostra não probabilística, o que não torna possível a expansão destes resultados ao restante da população. 0 estudo também não endereça o nível de confiança do consumidor em suas marcas preferidas e nos seus distribuidores preferidos, que seriam elementos a serem monitorados, em função de sua provável influência no processo de decisão de compra e consumo de alimentos. Para outros estudos, sugere-se a aplicação de uma pesquisa mais extensiva e com o concurso de amostra aleatória para que se possa estender os resultados para a população geral e ajudar as agências governamentais na elaboração de políticas e normas que venham a evitar o consumo de alimentos com data de validade vencida e os transtornos que dele podem advir.

Por outro lado, há que se considerar, também, que reportar em um questionário que possui conhecimentos sobre a data de validade e que leva isto em consideração 
nas decisões de compra e consumo, pode ser apenas um indicador de intenções e de respostas socialmente esperadas, o que pode contrastar com o comportamento real.

\section{Conflito de interesses}

Os autores declaram não haver conflito de interesses.

\section{Referências}

Aaker, D. A., Kumar, V., Day, G.S., \& Leone, R. (2009). A decision making perspective on marketing intelligence. Marketing Research (10th ed.). London: John Wiley \& Sons Ltd.

Ajzen, I. (1991). The theory of planned behavior. Organizational behavior and human decision processes, 50(2), 179-211.

Ajzen, I. (2012). Martin Fishbein's legacy: The reasoned action approach. The Annals of the American Academy of Political and Social Science, 640(1), 11-27. https://doi.org/10.1177/0002716211423363

Ajzen, I. (2020). The theory of planned behavior: Frequently asked questions. Human Behavior and Emerging Technologies, 2(4), 314324. https://doi.org/10.1002/hbe2.195

Ajzen, I., \& Fishbein, M. (1977). Attitude-behavior relations: Atheoretical analysis and review of empirical research. Psychological Bulletin, 84(5), 888-918. https://doi.org/10.1037/0033-2909.84.5.888

Andrade, E. C. B. (2006). Análise de alimentos: uma visão química da nutrição. Rio de Janeiro: Livraria Varela.

Agência Nacional de Vigilância Sanitária (ANVISA) (2019). Rotulagem de alimentos. Acessado em 18/07/2020. Disponível em http://portal.anvisa.gov.br/rotulagem-de-alimentos

Barcellos, M. D., Krystallis, A., de Melo Saab, M. S., Kügler, J. O., \& Grunert, K. G. (2011). Investigating the gap between citizens' sustainability attitudes and food purchasing behaviour: empirical evidence from Brazilian pork consumers. International Journal of Consumer Studies, 35(4), 391-402. https://doi.org/10.1111/j.1470-6431.2010.00978

Basil, D., Basil, M., \& Desphande, S. (2005). Nutrition labels: the effect of specific health concerns on decision quality and search time. Marketing and Public Policy Annual Conference. Washington DC.

Beneke, J., Greene, A., Lok, I., \& Mallett, K. (2012). The influence of perceived risk on purchase intent-the case of premium grocery private label brands in South Africa. Journal of Product \& Brand Management, 21(1), 4-14 https://doi.org/10.1108/10610421211203060

Bernardes, N. B., de Souza Facioli, L., Ferreira, M. L., de Moura Costa, R., \& de Sá, A. C. F. (2018). Intoxicação Alimentar: Um problema de Saúde Pública. Revista de Psicologia, 12(42), 894-906. https://doi.org/10.14295/idonline.v12i42.1373

Beumer, R. R., \& Kusumaningrum, H. (2003). Kitchen hygiene in daily life. International biodeterioration \& biodegradation, 51(4), 299-302. https://doi.org/10.1016/S0964-8305(03)00041

Blackwell, R. D., Miniard, P. W. \& Engel, J. F. (2005). Consumer Behavior (8ed.). Forth Worth: Dryden.

Bond, C. A., Thilmany, D. D., \& Bond, J. K. (2008). What to choose? The value of label claims to fresh produce consumers. Journal of Agricultural and Resource Economics, 33(3), 402-427. https://doi.org/10.22004/ag.econ.46559

Center for Disease Control and Prevention - CDCP. (2010). Surveillance for Foodborne Disease Outbreaks. Acessado em 18/09/2013. Disponível em

https://www.cdc.gov/mmwr/preview/mmwrhtml/mm6203a1.htm

Cronbach, L. J. (1951). Coefficient alpha and the internal structure of tests. Psychometrika, 16(3), 297-334. https://doi.org/10.1007/BF02310555

Cunha, L. M., Pinto de Moura, A., Lopes, Z., do Céu Santos, M., \& Silva, I. (2010). Public perceptions of food-related hazards: an application to Portuguese consumers. British Food Journal, 112(5), 522-543. https://doi.org/10.1108/00070701080001389

Damen, F. W. M., \& Steenbekkers, L. P. A. (2007). Consumer behaviour and knowledge related to freezing and defrosting meat at home: an exploratory study. British Food Journal, 109(7), 511-518. https://doi.org/10.1108/00070700710761509
De Moura, F. A., Nogueira, C. M., \& Gouvêa, M. A. (2012). Atributos determinantes na decisão de compra de consumidores de alimentos orgânicos. Agroalimentaria, 18(35), 75-86.

Diário Oficial da União Brasil. (1998). Portaria n.42, de 14 de Janeiro de 1998. A Secretaria de Vigilância Sanitária do MS aprova o regulamento técnico para rotulagem de alimentos embalados. Diário Oficial da União, (14)12; Seção 3. Brasil.

Espejel, J., Fandos, C., \& Flavián, C. (2009). The influence of consumer involvement on quality signals perception: An empirical investigation in the food sector. British Food Journal, 111(11), 12121236. https://doi.org/10.1108/00070700911001040

Ferreira, A. B., \& Lanfer-Marquez, U. M. (2007). Brazilian food labeling regulations. Revista de Nutrição, 20(1), 83-93. https://doi.org/10.1590/S1415-52732007000100009

Figueiredo, J. D. C., \& Csillag, J. M. (2010). Construindo Pontes Conceituais entre Atributos da Qualidade em Alimentos. Revista Brasileira de Gestão de Negócios, 12(34), 100-112.

Gish, J. (2009). A guide to expiration and sell-by dates on food. McClatchy - Tribune Business News. Washington. Acessado em 18/07/2020. Disponível em https://www.webmd.com/a-to-z-guides/features/do-foodexpiration-dates-matter\#1

Griffith, C. J. (2006). Food safety: where from and where to?. British Food Journal, 108(1), 6-15. https://doi.org/10.1108/00070700610637599

Grunert, K. G. (2005). Food quality and safety: consumer perception and demand. European review of agricultural economics, 32(3), 369391. https://doi.org/10.1108/00070700610637599

Guthrie, M. F., \& Kim, H. S. (2009). The relationship between consumer involvement and brand perceptions of female cosmetic consumers. Journal of Brand Management, 17(2), 114-133. https://doi.org/10.1057/bm.2008.28

Hair, J. F., Black, W. C., Babin, B. J., Anderson, R. E., \& Tatham, R. L. (1998). Multivariate data analysis. New Jersey: Prentice hall.

Hall-Phillips, A., \& Shah, P. (2017). Unclarity confusion and expiration date labels in the United States: A consumer perspective. Journal of Retailing and Consumer Services, 35, 118-126. https://doi.org/10.1016/j.jretconser.2016.12.007

Harcar, T., \& Karakaya, F. (2005). A cross-cultural exploration of attitudes toward product expiration dates. Psychology \& Marketing, 22(4), 353-371. https://doi.org/10.1002/mar.20063

Hayes, B. E. (2001). Medindo a satisfação do cliente: desenvolvimento e uso de questionários. Rio de Janeiro: Qualitymark.

Iwaya, G. H., \& Steil, A. V. (2019). Intenção de Compra de Alimentos Orgânicos: Revisão Sistemática dos Preditores Utilizados em Extensões da Teoria do Comportamento Planejado. Revista Administração em Diálogo-RAD, 21(3), 23-48. https://doi.org/10.23925/2178-0080.2019v21i3.40454

Johnson, T. D. (2009). Food safety reform moves closer to becoming a reality: Legislation now under consideration. The Nation's Health, 39(5), 1-33.

Kennedy, J., Jackson, V., Cowan, C., Blair, I., McDowell, D., \& Bolton, D. (2005). Consumer food safety knowledge: Segmentation of Irish home food preparers based on food safety knowledge and practice. British Food Journal, 107(7), 441-452. https://doi.org/10.1108/00070700510606864

Kim, C., \& Eun Huh, Y. (2019). Expiration date perception and food disposal decision. ACR North American Advances, 47, 158-163.

Knight, G. (2010). Time's Up: The importance of expiration dates to the consumer. Southern Utah University. PSY. Section 01 disp. Acessado em 13/01/2013. Disponível em http://www.suu.edu/faculty/white_l/MMPI/knight_MMPI_01.pdf

Konuk, F. A. (2015). The effects of price consciousness and sale proneness on purchase intention towards expiration date-based priced perishable foods. British Food Journal, 117(2), 793-804. https://doi.org/10.1108/BFJ-10-2013-0305

Kotler, P., \& Armstrong, G. (2010). Principles of Marketing. Harlow: Pearson Education.

Li, T., Messer, K. D., \& Kaiser, H. M. (2020). The impact of expiration dates labels on hedonic markets for perishable products. Food Policy, 93, 101894. https://doi.org/10.1016/j.foodpol.2020.101894 
Lindemann, I. L., Silva, M. T. D., César, J. G., \& Mendoza-Sassi, R. A. (2016). Leitura de rótulos alimentares entre usuários da atenção básica e fatores associados. Cadernos Saúde Coletiva, 24(4), 478486. https://doi.org/10.1590/1414-462×20160004034

Marins, B. R., Tancredi, R. C. P., \& Gemal, A. L. (2014). Segurança alimentar no contexto da vigilância sanitária: reflexões e práticas. Rio de Janeiro: EPSJV.

Mitchell, V. W. (1999). Consumer perceived risk: conceptualizations and models. European Journal of Marketing, 33(1/2), 163-195. https://doi.org/10.1108/03090569910249229

Moreira, P. (2009). O que está por trás da data de validade dos alimentos. Acessado em 21/06/2011. Disponível em https://www.humanasaude.com.br/noticias/o-que-esta-portras-da-data-de-validade-dos-alimentos

Samotyja, U. (2015). Influence of shelf life labelling on the sensory acceptability of potato snacks. British Food Journal, 117(1), 222233. https://doi.org/10.1108/BFJ-09-2013-0257

Scholes, T. (2010). The art and design of contemporary wine labels. Solana Beach: Santa Monica Press.

Sheth, J. (2020). Impact of Covid-19 on Consumer Behavior: Will the Old Habits Return or Die? Journal of Business Research, 117(9), 280-283. https://doi.org/10.1016/j.jbusres.2020.05.059

Tsiros, M., \& Heilman, C. M. (2005). The effect of expiration dates and perceived risk on purchasing behavior in grocery store perishable categories. Journal of Marketing, 69(2), 114-129. https://doi.org/10.1509/jmkg.69.2.114.60762
Vasconcelos, M. A. D. S., \& Melo, F. A. B. D. (2016). Conservação de alimentos. E-Tec Brasil. Acessado em 18/07/2020. Disponível em http://proedu.rnp.br/bitstream/handle/123456789/316/Cons Alimentos.pdf?sequence $=2$

Verbeke, W., \& Vackier, I. (2005). Individual determinants of fish consumption: application of the theory of planned behaviour. Appetite, 44(1), 67-82. https://doi.org/10.1016/j.appet.2004.08.006

Vignali-Ryding, D., García Sánchez, J., \& Vignali, G. (2003). The delicatessen and specialty food market in the North West. British Food Journal, 105(8), 551-558. https://doi.org/10.1108/00070700310497309

World Health Organization -WHO. (2017). Food safety and foodborne illness. Fact sheet. Acessado em 10/06/2019. Disponível em at: https://www.who.int/news-room/fact-sheets/detail/food-safety

Yeung, R. M., \& Morris, J. (2001). Food safety risk: Consumer perception and purchase behaviour. British Food Journal, 103(3), 170-187. https://doi.org/10.1108/00070700110386728.

Zandonadi, R. P., Botelho, R. B. A., Sávio, K. E. O., Akutsu, R. de C., \& Araújo, W. M. C. (2007). Atitudes de risco do consumidor em restaurantes de auto-serviço. Revista de Nutrição, 20(1), 19-26. https://dx.doi.org/10.1590/S1415-52732007000100002 